\title{
Predicting the potential distribution of an endangered cryptic subterranean mammal from few occurrence records
}

\author{
Craig R. Jackson ${ }^{\mathrm{a}, \mathrm{c}}$, Mark P. Robertson ${ }^{\mathrm{b}, *}$ \\ a Mammal Research Institute, Department of Zoology and Entomology, University of Pretoria, Pretoria 0002, South Africa \\ ${ }^{\mathrm{b}}$ Centre for Invasion Biology, Department of Zoology and Entomology, University of Pretoria, Pretoria 0002, South Africa \\ ${ }^{\mathrm{c}}$ Department of Biology, Norwegian University of Science and Technology (NTNU), Realfagbygget, N-7491 Trondheim, Norway
}

\section{A R T I C L E I N F O}

\section{Article history:}

Received 3 December 2009

Accepted 30 June 2010

\section{Keywords:}

Conservation planning

Ecological niche models

Juliana's golden mole

Neamblysomus julianae

Small sample size

Species distribution modelling

\begin{abstract}
A B S T R A C T
Knowledge of geographical distributions and habitat preferences are central to the conservation and management of threatened species. Ecological niche models can be used to map potentially suitable habitat, making them valuable tools in conservation biology. These models can assist in searching for new populations of species with poorly known distributions and can also be used to guide area selection for systematic biodiversity planning. These models have traditionally required ten or more occurrence records for calibration and this has limited the use of these tools in conservation biology, since many threatened species are known from fewer records. However, recently models have been successfully calibrated using few records. To illustrate this, we developed an ecological niche model to map the potential distribution of the endangered Juliana's golden mole (Neamblysomus julianae) in South Africa so that it could be used in searching for unrecorded populations and for area selection in systematic biodiversity plans. A model was calibrated in Maxent using only four occurrence records. Predictor variables included various bioclimatic, soil and vegetation types. The model identified limited suitable habitat within the map region. The first model facilitated the identification of two previously unrecorded populations. A second model was calibrated using the two additional occurrence records. This increased the proportion of correctly predicted presence records. Jackknife analyses indicated that the models were successful at predicting known presences as suitable. This paper demonstrates the use of ecological niche modelling to conservation of a cryptic endangered species with a poorly known distribution and discusses issues that are relevant for the application of this approach to other species.
\end{abstract}

(c) 2010 Elsevier GmbH. All rights reserved.

\section{Introduction}

Knowledge of geographical distributions and habitat preferences are central to the conservation and population management of threatened species (Guisan et al., 2006; Thomaes et al., 2008). Ecological niche models have been widely applied in conservation biology to predict the potential distributions of species using correlative models that exploit a species-environment relationship (Anderson et al., 2009; Chefaoui et al., 2005; De Siqueira et al., 2009; Peterson, 2001; Raxworthy et al., 2007; Rushton et al., 2004; Titeux et al., 2007). Ecological niche models require occurrence records and a set of environmental predictor variables in order to predict a species' potential distribution (Gaubert et al., 2006; Peterson, 2001). Many species of conservation concern are cryptic or range-restricted and often very few occurrence records are available for these species (Pearson et al., 2007). Recently success has been achieved in calibrating ecological niche models with fewer

\footnotetext{
* Corresponding author. Tel.: +27 12 4204396; fax: +27 124203210.

E-mail address: mrobertson@zoology.up.ac.za (M.P. Robertson).
}

than ten occurrence records (De Siqueira et al., 2009; Pearson et al., 2007). In view of this, ecological niche models have the potential to make a contribution to conservation in two important ways, especially for species with few occurrence records. First, they can be used to direct field surveys that are designed to search for new populations of rare and poorly known species by identifying potentially suitable areas (Bourg et al., 2005; De Siqueira et al., 2009; Guisan et al., 2006). Second, they can be used in conservation area selection for systematic biodiversity plans (Cowling et al., 2003; Loiselle et al., 2003; Wilson et al., 2005). This planning process identifies parcels of land that have high biodiversity value using the principles of systematic biodiversity planning (Driver et al., 2003; Margules \& Pressey, 2000). These biodiversity plans require a set of targets to be defined, which are usually based on several elements of biodiversity (Driver et al., 2003) but can include species distributions and particularly threatened or range-restricted species (Loiselle et al., 2003; Wilson et al., 2005). In this way species of conservation concern will gain a level of protection from threatening processes by being part of a network of conservation areas, whilst the biodiversity of the region will simultaneously be conserved. 
The endangered Juliana's golden mole (Neamblysomus julianae; Chrysochloridae) is a small ( $35 \mathrm{~g})$, habitat-specific mammal that is particularly difficult to study due to its subterranean lifestyle (Jackson et al., 2008, 2009). Despite occurring less than $15 \mathrm{~km}$ from the centre of South Africa's capital city, Pretoria, this species was only described in 1972 (Bronner \& Bennett, 2005). Although recent studies have investigated certain aspects of its biology (Jackson et al., 2007, 2008, 2009), it is still relatively poorly known. The distribution range of the species is highly restricted. It is known to occur on the Bronberg Ridge (BR) in eastern Pretoria, $120 \mathrm{~km}$ north in the Nylsvley Nature Reserve (NNR), and $350 \mathrm{~km}$ east in the south western Kruger National Park (KNP) (Bronner \& Bennett, 2005). Based on dental characteristics (Bronner, 1995) and recent genetic evidence (Maree, pers. comm.), animals from the KNP population differ significantly from the other two populations and evidence suggests that the KNP population could be treated as a separate species. Juliana's golden mole thus appears to be restricted to the BR and NNR areas.

The BR is less than $15 \mathrm{~km}$ in length and the suitable sandy soils are on average less than $1 \mathrm{~km}$ in width (Bosch, 2004). The NNR population is described from the reserve where approximately 800 ha constitutes suitable habitat (Jackson, 2007). Based on the current understanding of its distribution, the geographic areas occupied by these two populations are very small and not adequate to ensure the long-term persistence of the species. The small size and fossorial lifestyle means that this species has poor dispersal capabilities. Unlike mole-rats that are powerful diggers, excavating soil with their large teeth, golden moles use only their forelimbs and have far weaker tunnelling capabilities that restricts them to softer soil types. They are thus extremely susceptible to habitat fragmentation, as even relatively minor obstacles such as roads can constitute impenetrable barriers. These factors in combination with small geographical ranges have resulted in ten of the 21 golden mole species appearing on the IUCN red list, with an additional two species listed as data deficient. Of these species, five are listed amongst the ten most endangered mammal species in South Africa (IUCN, 2004).

Recently a thorough ecological assessment that specifically documented the species' habitat requirements was undertaken (Jackson et al., 2008). Using this information we aimed firstly to make use of ecological niche modelling to produce a potential distribution map for Juliana's golden mole that could be used to search for new populations. Secondly, we aimed to produce a model that could be used for area selection in systematic biodiversity planning.

\section{Methods}

Study region

The study region was defined as four of South Africa's provinces: Gauteng; North West; Mpumalanga; and Limpopo (Fig. 1). This region is dominated by the savanna biome (Mucina \& Rutherford, 2006). This area was chosen since the species is only known from savanna vegetation types (Jackson et al., 2008). Rainfall in the savanna biome is highly seasonal, resulting in wet summers and dry winters. The region is generally warm, with a sub-tropical to tropical thermal regime and is generally free of frost (Mucina \& Rutherford, 2006).

\section{Occurrence records}

Occurrence records for the species were collected as part of a study on the habitat utilisation of the species (Jackson et al., 2008). The species was initially known only from the Bronberg Ridge and in the vicinity of Nylsvley Nature Reserve (Fig. 1). We did not con- sider the Kruger National Park population, as all available evidence indicates that this is probably a different species. For each of these populations several occurrence records were collected during the habitat study (Jackson et al., 2008). Based on concerns about spatial autocorrelation, only records that were further than $10 \mathrm{~km}$ apart were selected (following Pearson et al., 2007). This resulted in only three occurrence records that could be used for model calibration. We produced a simple overlay model, which allowed us to identify potentially suitable habitats based on soil classes (ARC-ISCW, 2004) and vegetation types (Mucina \& Rutherford, 2006) (data not shown). This simple model assisted us in discovering another population of the species. This was approximately $20 \mathrm{~km}$ to the east of the population in the Nylsvley Nature Reserve. As this new occurrence record was more than $10 \mathrm{~km}$ from existing records we thus had a dataset of four records. An ecological niche model was then produced (in Maxent) using only these four occurrence records (details below). Using this model we conducted another survey and found two additional populations of the species that had not previously been recorded.

\section{Predictor variables}

We used a set of interpolated bioclimatic predictor variables from Worldclim (www.worldclim.org, Hijmans et al., 2005), a map of vegetation types (Mucina \& Rutherford, 2006) and a map of soil classes (ARC-ISCW, 2004) as the set of predictor variables. Soil characteristics and vegetation have been shown to be important to this species (Jackson et al., 2007, 2008). We selected the set of bioclimatic predictor variables that were likely to summarise temperature and moisture availability, which are important for predicting distributions (Beaumont et al., 2009). The bioclimatic predictor variables included: temperature seasonality; maximum temperature of warmest month; minimum temperature of coldest month; mean temperature of warmest month; annual precipitation; precipitation seasonality; precipitation of wettest quarter; and precipitation of warmest quarter. The bioclimatic variables were available at a spatial resolution of 30 arc seconds. The vegetation and soil maps were converted to rasters at this resolution using ArcMap v. 9.3.

\section{Modelling}

We used Maxent (Phillips \& Dudik, 2008; Phillips et al., 2006) to estimate the potential distribution of the species. Maxent estimates the ecological niche of a species by determining the distribution of maximum entropy, subject to the constraint that the expected value of each environmental variable (or functions of these) under this estimated distribution matches its empirical average (Phillips et al., 2006). Maxent makes use of presence records and a set of background values drawn from the entire study region. Default parameters in Maxent were used (version 3.1.0) to produce models: feature selection automatic; regularisation multiplier at unity; maximum iterations 500; convergence threshold $10^{-5}$; and random test percentage at zero. The predictor variables used to calibrate the models included: temperature seasonality; maximum temperature of warmest month; minimum temperature of coldest month; mean temperature of warmest month; annual precipitation; precipitation seasonality; precipitation of wettest quarter; precipitation of warmest quarter; vegetation types; and soil classes. We produced maps of the potential distribution of the species using the logistic output format (Phillips \& Dudik, 2008). We chose Maxent because it requires only presence data, it has been shown to perform well with small sample sizes (Pearson et al., 2007), and has performed favourably when compared with alternative approaches (Elith et al., 2006; Wisz et al., 2008). 


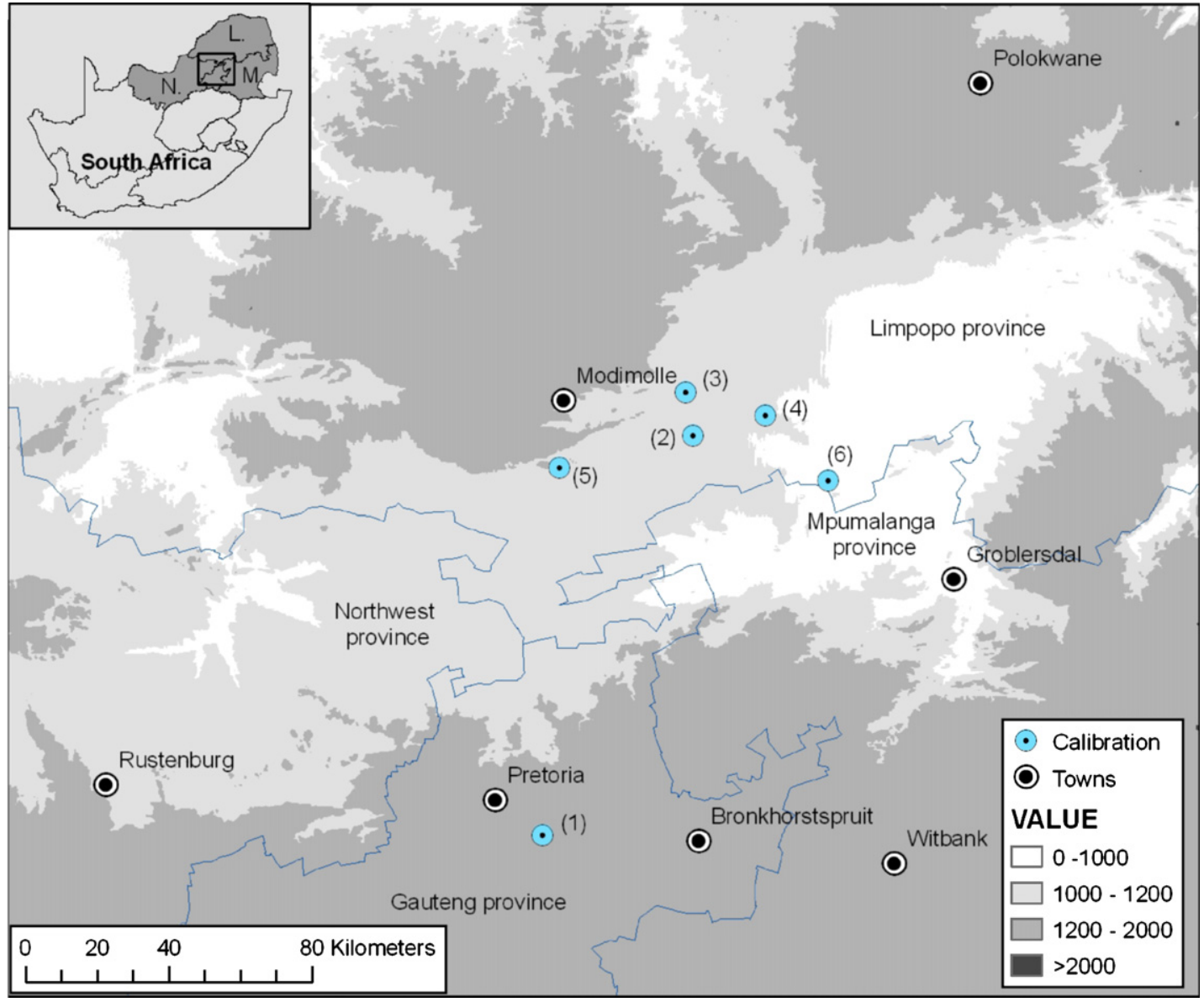

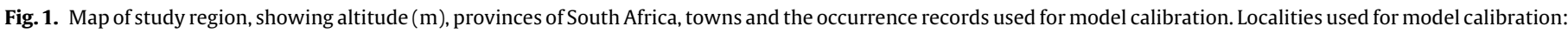

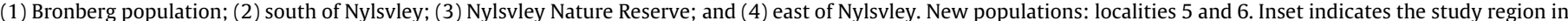
South Africa, the provinces include: Gauteng; North West (N.); Mpumalanga (M.); and Limpopo (L.).

The National Landcover Classification of 2000 for South Africa was used to identify those parts of the map region that have been transformed or degraded and are thus unlikely to support populations of the target species. The landcover map was generated by classifying Landsat imagery covering the whole of South Africa into 48 different landcover classes. We reclassified the landcover map so that all natural cover classes were assigned a value of one (suitable) and all classes representing cultivation, degradation, urban areas and mining (i.e. unsuitable) were assigned a value of zero. This new landcover map was used to assign all areas that were degraded or transformed as "unsuitable" to the species by multiplying this map with the potential distribution map (Anderson \& Martinez-Meyer, 2004).

\section{Model evaluation}

Since we had very few occurrence records with which to calibrate and evaluate models, we followed the jackknife approach developed by Pearson et al. (2007). In this approach the model is calibrated using $n-1$ records and tested using one record. This process is repeated until all records have been used for testing. A decision threshold is required to convert the continuous values (0-1) from predictions into a map indicating "presence" and "absence" (Pearson et al., 2007). We chose the lowest predicted value associated with our set of presence records, which has been referred to as the 'lowest presence threshold' (LPT; Pearson et al., 2007). It is considered to be a conservative approach, as it identifies grid cells that are at least as suitable as those where the species has been recorded (Pearson et al., 2007). We did not use the more liberal 10\% fixed threshold approach of Pearson et al. (2007) as we felt that the commission error rate would be unacceptably high. For this fixed threshold approach, the threshold is set at the lowest $10 \%$ of all predicted values in the model (Pearson et al., 2007).

We wrote a program in $\mathrm{R}$ ( $\mathrm{R}$ Development Core Team, 2005) to prepare the datasets for calibration and testing using the jackknife approach. We used the software program supplied by Pearson et al. (2007) to calculate a $p$-value for assessing significance of the jackknife predictions. We report the proportion of records correctly predicted and the $p$-value for the jackknife predictions. Given the small sample sizes and conservative threshold used here, we would consider a value of 0.5 for the proportion records correctly predicted to be acceptable. Pearson et al. (2007) obtained proportions ranging from 0 to 0.33 records correctly predicted with models calibrated using Maxent with four to six records and using the LPT threshold.

We also undertook field surveys to evaluate the suitability of several sites and to compare these with the suitability values from the models. For these surveys we visited 21 sites that were predicted to be suitable and three sites that were predicted to be unsuitable to determine whether the species was present at these sites. All sites were separated by a minimum distance of $1 \mathrm{~km}$ from each other or from existing populations. We used the suitability map generated from the model to identify sites for inspection. We did not remove the degraded and transformed sites from this suitability map as we were concerned about possible misclassification errors in the original land cover map. We used a Trimble Juno GPS (www.trimble.com/junosb.shtml) onto which we loaded the suit- 
ability map generated from the model. By being able to display our geographical position on the suitability map we could easily and accurately navigate to areas of high predicted suitability. This helped to reduce the time and cost required to search for new populations. At sites predicted by the model to be suitable or unsuitable two experienced observers spent at least 10 min searching an area of 2-3 ha for burrows. The species was considered to be present if we found networks of sub-surface foraging burrows that are characteristic of this species (Jackson, 2007). If no burrows could be found then the species was considered to be absent but we further classified the site as being "suitable" or "unsuitable". This classification was based on visual assessments of the soil and vegetation based on our experience in conducting habitat surveys (Jackson et al., 2007, 2008). We assessed the soil texture to ensure that it was soft, sandy and had a low clay content. These were found to be important factors determining habitat suitability of this species (Jackson et al., 2007). The presence of tall ( $>4 \mathrm{~m}$ ) broad-leaf trees (Terminalia sericea and Burkea africana) and an absence of areas dominated by fine-leaf tree species (e.g. Acacia spp., Peltophorum africanum and Dichrostachys cinerea) were also used as an indicator of suitable habitat. The fine-leaf species tend to be associated with hard soils that have relatively high clay content, while the broadleaf species tend to be associated with soft sandy soils. In addition to confirming the absence of the species at three locations by active searching, we were also able to confirm that the habitat that was predicted to be unsuitable by the model was indeed unsuitable by assessing the vegetation composition from the road at a further 77 locations.

\section{Results}

The first model, calibrated with only four occurrence records, indicated a small part of the map region as being suitable for the species (Fig. 2). Large areas of unsuitable habitat $(<0.4)$ separate the areas of high suitability $(>0.8)$. The jackknife analysis indicated that the models were successful at predicting known presences as suit-

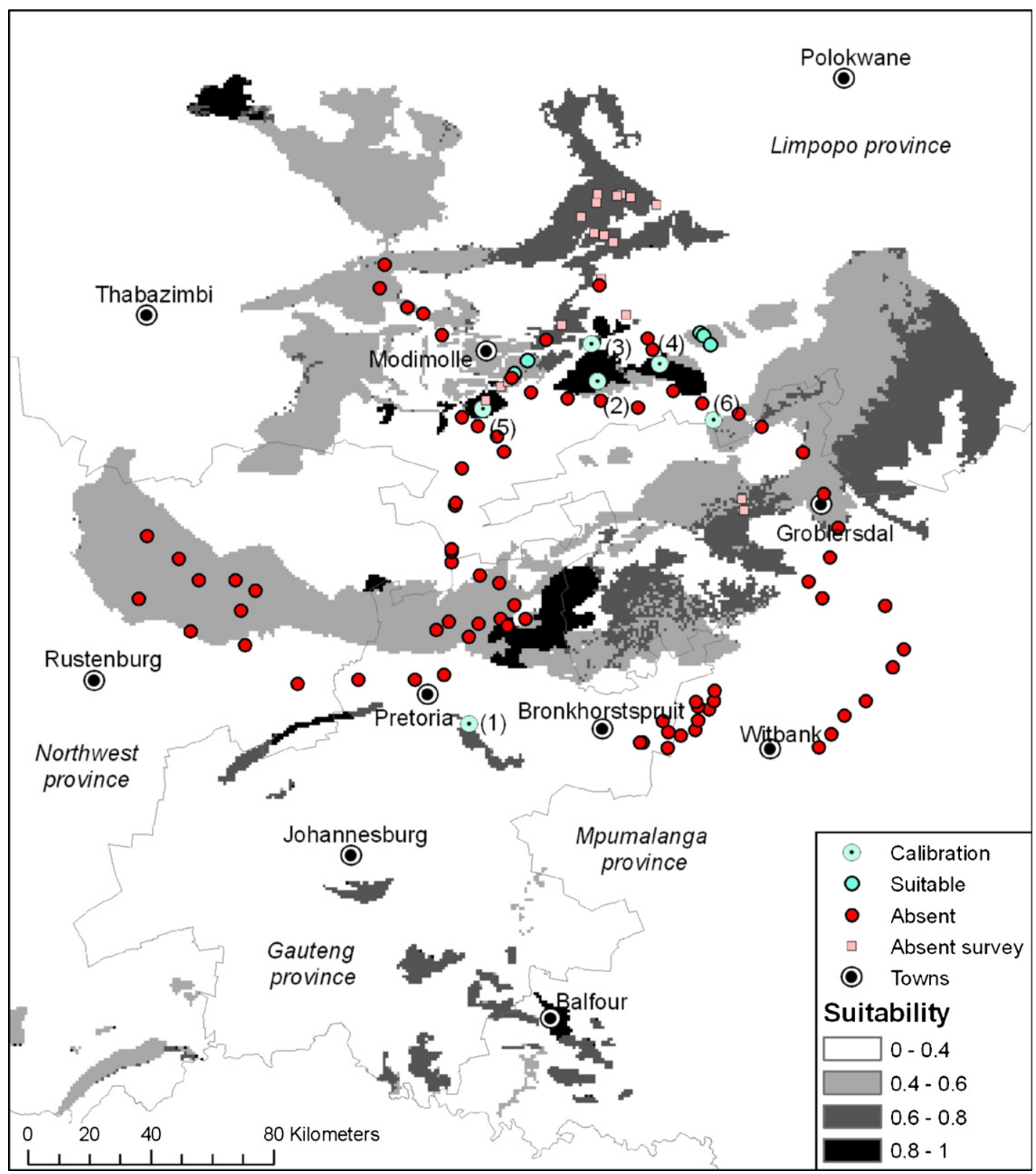

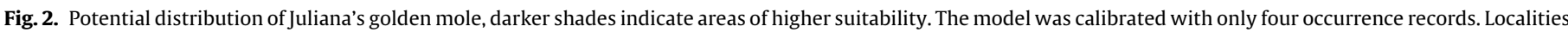

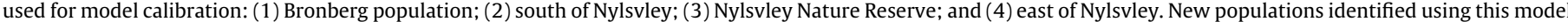
are indicated as localities 5 and 6. 


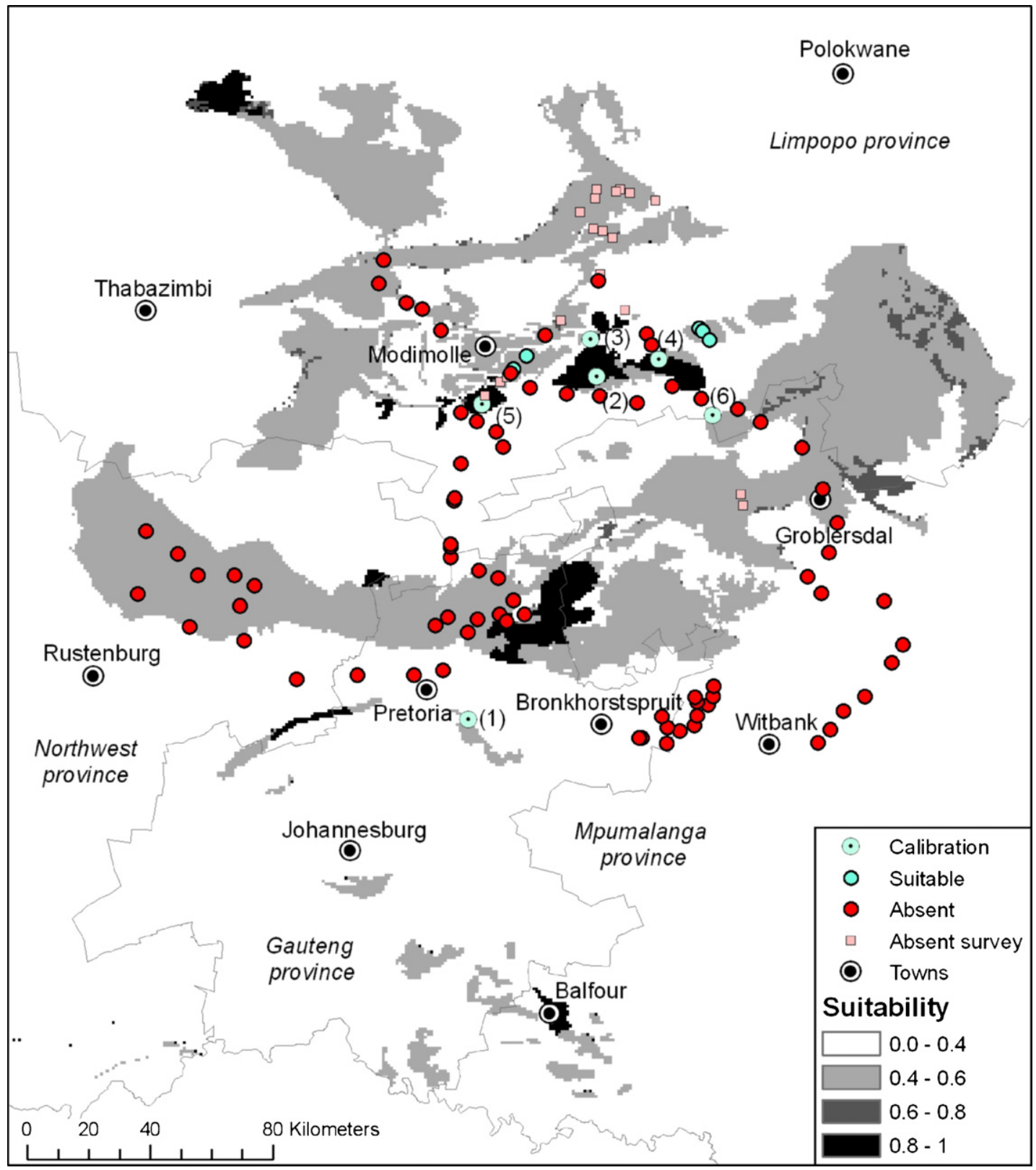

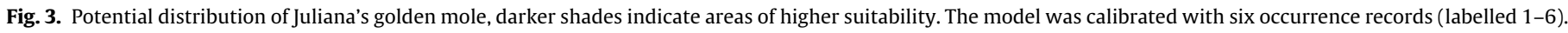

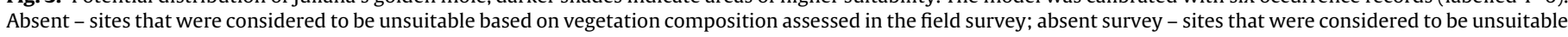

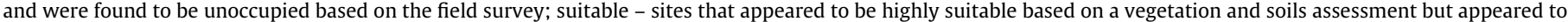
be unoccupied.

able (proportion correctly predicted: $0.5 ; p=0.00054$ ). All four of the occurrence records were located in areas that were predicted to be highly suitable for the species (Fig. 2). Using this model we visited a number of areas that were predicted to be suitable for the species. We were able to confirm the presence of the species at another two sites in the vicinity of the Nylsvley population, that were in areas predicted to be suitable by the model. The first site was ca. $20 \mathrm{~km}$ due south of the town of Modimolle and the second site was ca. $80 \mathrm{~km}$ south east of Modimolle (localities 5 and 6 in Fig. 2). These sites were further than $35 \mathrm{~km}$ (locality 5) and $24 \mathrm{~km}$ (locality 6), respectively, from the nearest known occurrence of the species. This increased the calibration set from four to six occurrence records.

The second model was calibrated with six occurrence records. This model also indicated a small part of the map region as being suitable for the species (Fig. 3). This model did not dif- fer considerably from the first model, except that certain areas had lower suitability values than in the first model. The jackknife analysis indicated that the models were successful at predicting known presences as suitable (proportion correctly predicted: 0.67 ; $p=0.000002$ ). The proportion of correctly predicted known presences increased from 0.5 for the first model to 0.67 for the second model. We conducted a field survey and found a number of sites (based on high predicted suitability) that appeared to be highly suitable based on a vegetation and soils assessment but appeared to be unoccupied (points labelled 'Suitable' in Fig. 3). We also identified several areas to the north of Modimolle that were predicted to be suitable but that appeared to be unsuitable based on the field survey (points labelled as 'Absent survey' in Fig. 3). We were also able confirm that 77 sites which were predicted to be unsuitable as being unsuitable based on vegetation composition (points labelled as 'Absent' in Fig. 3). 


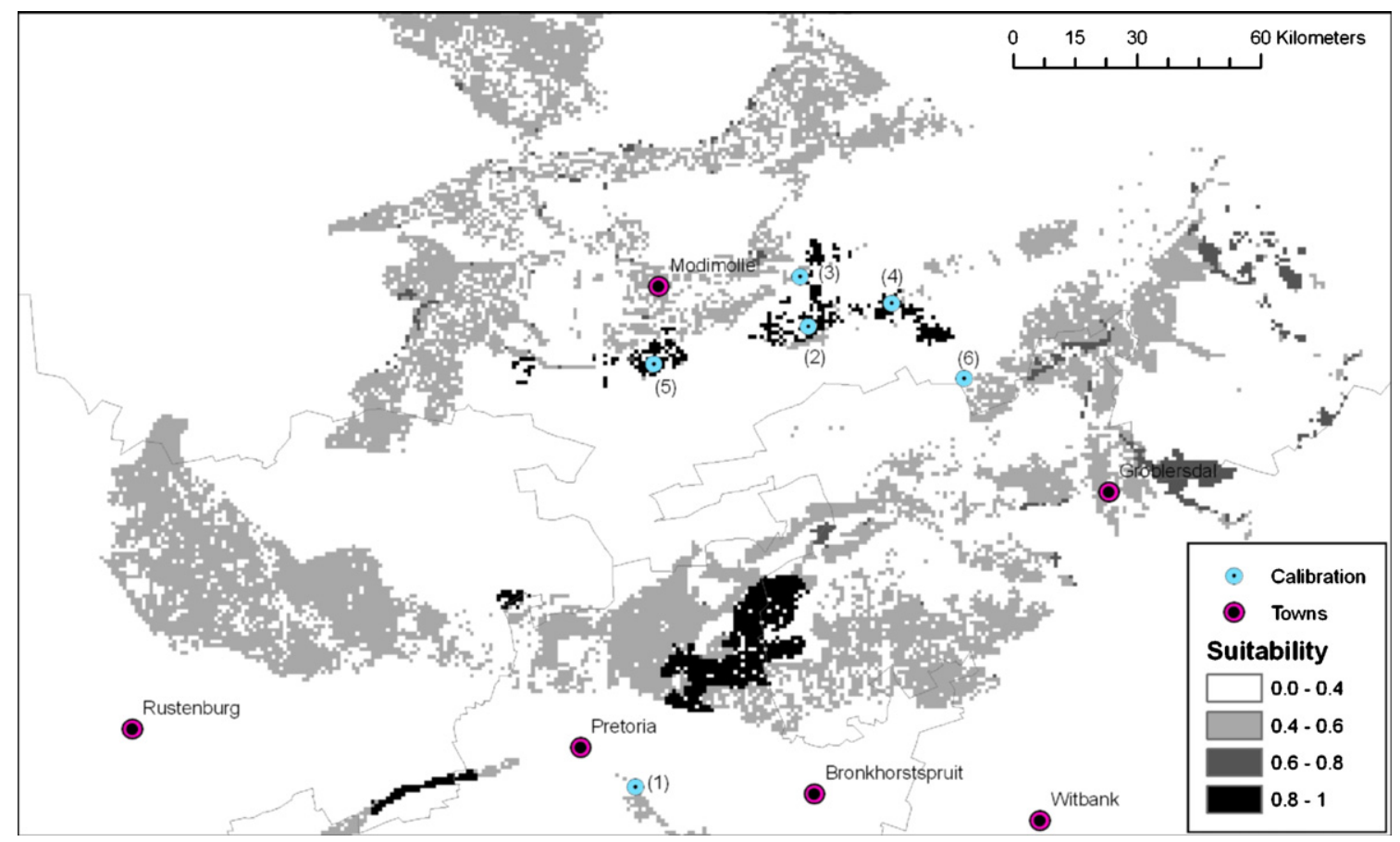

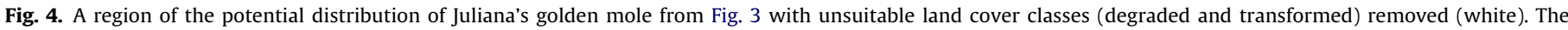
provincial boundaries are shown as grey lines.

When unsuitable land cover classes (degraded and transformed) are taken into account then the area predicted to be suitable for the species is drastically reduced and becomes highly fragmented (Fig. 4). In particular, the areas of habitat that are predicted to be highly suitable in the vicinity of Modimolle appear highly fragmented. This appears to be largely due to clearing of natural vegetation for the cultivation of crops. In the vicinity of Pretoria, the suitable habitat is also reduced. Much of this is due to the rapid expansion of the city of Pretoria eastwards into suitable habitat.

\section{Discussion}

\section{The models}

The models that we have presented here have been successful at identifying regions that are suitable for the species. The first model that was calibrated with only four occurrence records was useful as it allowed us to identify further sites that were occupied by the species. The jackknife analysis indicated that this model successfully predicted known presences as suitable $50 \%$ of the time. However, this proportion implies that the model was unsuccessful and omitted known presences $50 \%$ of the time. We consider this to be an acceptable proportion, given the small sample size and conservative threshold that we used for model evaluation. The second model that was calibrated with six occurrence records provided us with a more robust prediction as the proportion of known presences correctly predicted was higher $(0.67)$ than the first $(0.5)$.

For both models the sample size is considered to be small. However, others have successfully produced models using few occurrence records. Pearson et al. (2007) successfully produced models for geckos in Madagascar (using Maxent) with as few as five occurrence records, but were unsuccessful when using only four records (as success of predicting known presences was zero for this species). De Siqueira et al. (2009) produced a model for a rare plant in Brazil based on seven occurrence records using GARP modelling software.
The models that we present should be interpreted with care since the sample sizes are small. Pearson et al. (2007) caution that these models should not be interpreted as indicating the actual limits of the range of the species but should rather be interpreted as highlighting areas with similar environmental conditions to places where the species currently maintains populations. These models can thus be considered to represent a conservative potential distribution of the species. This is because regions that are environmentally similar to those used for model calibration will be highlighted as suitable regions for the species. However, with a small dataset it is possible that the potential distribution could be underestimated, as the calibration dataset may not represent all suitable environmental conditions. In addition, the models do not incorporate biotic interactions and dispersal limitation that would be required to model the realised distribution (Jiménez-Valverde et al., 2008).

Although we have done a limited number of field surveys, a more extensive effort is required. In addition, specimens of the species captured at sites where burrows have been found will further increase confidence in the model, however capturing individuals is extremely difficult and time-consuming (Jackson et al., 2009). During field surveys it is important to consider that the model may identify areas that are highly suitable but that are not occupied by the species (Gibson et al., 2007; Greaves et al., 2006; Pearson \& Dawson, 2003; Soberon \& Peterson, 2005). This could be due to a genuine commission error by the model or because the species was unable to disperse to these suitable areas, due to biotic interactions, or due to historical factors such as dispersal barriers (Pearson \& Dawson, 2003; Soberon \& Peterson, 2005). This species is a poor disperser as it is dependent on soft sandy soils and does not readily move on the surface of the soil. From field surveys we identified several areas that appeared to be suitable, based on vegetation and soil assessments, but that were not occupied. As these models are considered to represent potential distributions, we evaluated the models with presence data only and not absence data. Absence data should not be used to evaluate potential distribution models as these models are likely to identify regions that are suitable 
but not occupied. Further evaluation of the model requires new presence records, physiological data or translocation experiments (Jiménez-Valverde et al., 2008).

\section{Searching for additional populations}

The models developed here can be used to guide field surveys to search for additional populations of this species. This approach has been successful for other species (Bourg et al., 2005; De Siqueira et al., 2009; Guisan et al., 2006). Finding new populations is particularly important for Juliana's golden mole, since the species' habitat is being rapidly transformed and fragmented (Fig. 4). The Bronberg population near Pretoria is particularly vulnerable to fragmentation by humans (Jackson, 2007). Other presently unrecorded populations need to be identified and their conservation status assessed in order for them to be afforded protection from threatening processes such as fragmentation and transformation. Areas that are predicted as being highly suitable should be surveyed first in order to increase the likelihood of finding new populations in the short term. In particular, the region of high suitability to the northeast of Pretoria and the small region to the northwest should be investigated. An unconfirmed report of golden mole tunnels east of Groblersdal (J. Wilson, pers. comm.) may occur within the predicted area in this vicinity and needs to be investigated. The region to the west of Pretoria, the region around Balfour and the region to the north of Thabazimbi also warrant further investigation. Although areas with high suitability are most likely to support populations, areas with lower suitability should not be overlooked. Pearson et al. (2007) suggest that a threshold below the lowest predicted present threshold (LPT) should be used to guide field surveys. They found that the LPT decreased as sample size increased (Pearson et al., 2007), implying that the LPT can be quite conservative and that the species could be present at suitability values lower than the LPT. In our model, the value of LPT was 0.48 and the threshold that we used in the maps for undertaking the field surveys was 0.4 .

Searching for new populations can be aided using a model that incorporates unsuitable land cover classes to reduce the areas that are predicted as suitable (e.g. Fig. 4). However, care is required with this approach, as the landcover map may have misclassified some areas as being unsuitable when they are actually suitable. The apparent extent of transformed habitat could be influenced by the spatial resolution of the landcover map and the predictor variable grid. The time since the landcover map was generated should also be taken into consideration. In our case almost nine years had elapsed since the landcover map was generated. This highlights the importance of conducting field surveys to evaluate the model.

\section{Systematic biodiversity planning}

It is hoped that these models will be used to guide biodiversity planning. A number of provinces in South Africa have recently completed conservation plans (e.g. Mpumalanga, North West and KwaZulu-Natal provinces). These models could be used to set selection targets for land units based on their value as suitable habitat for this species, which is currently listed as endangered (IUCN, 2004). This will go some way towards preventing further transformation and degradation of suitable habitat for this species. The appropriate threshold to use for conservation area selection will be higher than that used for searching for new populations, most likely set at LPT. This is due to the difference in cost of commission and omission errors in these two applications (Fielding \& Bell, 1997). In the case of conservation area selection the land parcels selected should be highly suitable and must be occupied by the species. This is because the cost of conserving unsuitable land will be high, as commission errors are costly (Loiselle et al., 2003). In contrast, when using the model to search for new populations omission errors will be more costly as it would be preferable to increase survey effort than fail to detect a population.

\section{Ecological niche models and small sample sizes}

The example that we present here for Juliana's golden mole suggests that ecological niche models can make a valuable contribution to conservation, even for species with few occurrence records. This example is interesting because we had few occurrence records for a habitat-specific species with poor dispersal abilities. Therefore not all suitable habitat will always be occupied and absence data will tend to be unreliable as it is not necessarily indicative of unsuitable habitat. Gibson et al. (2007) experienced the same problem with parrots in Australia. As we initially had no absence data and because absence data would be unreliable we could not use models that require presence-absence data (e.g. Guisan et al., 2006). With plants for which quadrat sampling of a region has been undertaken absence can often be inferred (Guisan et al., 2006). This is usually not the case for animals, as systematic surveys of entire regions are rarely undertaken. As the sample size was small we had to use a presence-only approach that could make predictions using few occurrence records (De Siqueira et al., 2009; Pearson et al., 2007). The approach used for model evaluation was also determined by the small sample size, and the recently described jackknife approach was adopted (Pearson et al., 2007). Field surveys were used to find new populations and to assess model predictions. Detection in suitable habitat was done by indirect means (finding foraging tunnels), which made data collection and model evaluation easier than if we had been forced to trap the animal in order to obtain occurrence data. Not all animal species can be detected using indirect cues (especially cryptic or nocturnal species) and the chance of omission errors is high for these species (Gibson et al., 2007). Many of the issues discussed here are likely to be more broadly applicable to other small subterranean mammals and also to other poorly known animal and plant species for which conservation action is urgently required. In southern Africa alone, there are 21 golden mole species whose distribution is poorly understood and half of which occur on the IUCN red list. Producing similar models would be invaluable in attempting to document habitats, as this knowledge underpins all conservation efforts.

We have demonstrated the application of ecological niche models to the conservation of an endangered species for which few occurrence records are available. The models had great conservation value as they successfully predicted previously unrecorded populations of Juliana's golden mole. The approach that we have presented can be applied to other rare and/or endangered species for which few occurrence records exist. This study demonstrates the value of using ecological modelling for the conservation and management of endangered species.

\section{Acknowledgements}

Trine H. Setsaas and Simon Byron are thanked for assisting with field surveys. The WWF Green Trust, a partnership between WWF South Africa and Nedbank (South Africa), kindly funded part of this study.

\section{References}

ARC-ISCW. (2004). Overview of the agricultural natural resources of South Africa. ARC-ISCW report no. GW/A/2004/13. Pretoria, South Africa: Agricultural Research Council-Institute for Soil, Climate and Water.

Anderson, B. J., Arroyo, B. E., Collingham, Y. C., Etheridge, B., Fernandez-De-Simon, J. Gillings, S., et al. (2009). Using distribution models to test alternative hypotheses about a species' environmental limits and recovery prospects. Biological Conservation, 142, 488-499. 
Anderson, R. P., \& Martinez-Meyer, E. (2004). Modeling species' geographic distributions for preliminary conservation assessments: An implementation with the spiny pocket mice (Heteromys) of Ecuador. Biological Conservation, 116, 167-179.

Beaumont, L. J., Gallagher, R. V., Thuiller, W., Downey, P. O., Leishman, M. R., \& Hughes, L. (2009). Different climatic envelopes among invasive populations may lead to underestimations of current and future biological invasions. Diversity and Distributions, 15, 409-420.

Bosch, P. J. A. (2004). Supplementary discussion of the results of the geological investigations above Willow Quarries on Zwavelpoort $373 \mathrm{JR}$ and impact on the Bronberg Mountain. Pretoria, South Africa: Council for Geoscience Internal Report.

Bourg, N. A., Mcshea, W. J., \& Gill, D. E. (2005). Putting a cart before the search: Successful habitat prediction for a rare forest herb. Ecology, 86, 2793-2804.

Bronner, G. N. (1995). Systematic revision of the golden mole genera Amblysomus, Chlorotalpa and Calcochloris (Insectivora: Chrysochloromorpha: Chrysochloridae). PhD thesis. Durban, South Africa: University of Natal.

Bronner, G. N., \& Bennett, N. C. (2005). Order Afrosoricida. In J. D. Skinner, \& C. T. Chimimba (Eds.), The mammals of the southern African subregion. Cambridge: Cambridge University Press.

Chefaoui, R. M., Hortal, J., \& Lobo, J. M. (2005). Potential distribution modelling, niche characterization and conservation status assessment using GIS tools: A case study of Iberian Copris species. Biological Conservation, 122, 327-338.

Cowling, R. M., Pressey, R. L., Rouget, M., \& Lombard, A. T. (2003). A conservation plan for a global biodiversity hotspot-the Cape Floristic Region, South Africa. Biological Conservation, 112, 191-216.

De Siqueira, M. F., Durigan, G., De Marco, P., Jr., \& Peterson, A. T. (2009). Something from nothing: Using landscape similarity and ecological niche modeling to find rare plant species. Journal for Nature Conservation, 17, 25-32.

Driver, A., Cowling, R. M., \& Maze, K. (2003). Planning for living landscapes: Perspectives and lessons from South Africa. Cape Town: Botanical Society of South Africa.

Elith, J., Graham, C. H., Anderson, R. P., Dudik, M., Ferrier, S., Guisan, A., et al. (2006). Novel methods improve prediction of species' distributions from occurrence data. Ecography, 29, 129-151.

Fielding, A. H., \& Bell, J. F. (1997). A review of methods for the assessment of prediction errors in conservation presence/absence models. Environmental Conservation, 24, 38-49.

Gaubert, P., Papes, M., \& Peterson, A. T. (2006). Natural history collections and the conservation of poorly known taxa: Ecological niche modelling in central African rainforest genets (Genetta spp.). Biological Conservation, 130, 106-117.

Gibson, L., Barrett, B., \& Burbidge, A. (2007). Dealing with uncertain absences in habitat modelling: A case study of a rare ground-dwelling parrot. Diversity and Distributions, 13, 704-713.

Greaves, G. J., Mathieu, R., \& Seddon, P. J. (2006). Predictive modelling and ground validation of the spatial distribution of the New Zealand long-tailed bat (Chalinolobus tuberculatus). Biological Conservation, 132, 211-221.

Guisan, A., Broennimann, O., Engler, R., Vust, M., Yoccoz, N. G., Lehmann, A., et al. (2006). Using niche-based models to improve the sampling of rare species. Conservation Biology, 20, 501-511.

Hijmans, R. J., Cameron, S. E., Parra, J. L., Jones, P. G., \& Jarvis, A. (2005). Very high resolution interpolated climate surfaces for global land areas. International Journal of Climatology, 25, 1965-1978.

IUCN. (2004). Red data book of the mammals of South Africa: A conservation assessment. South Africa: CBSG Southern Africa, Conservation Breeding Specialist Group (SSC/IUCN), Endangered Wildlife Trust.

Jackson, C. R. (2007). The Ecology and Conservation of Juliana's golden mole (Neamblysomus julianae). MSc thesis. Pretoria, South Africa: University of Pretoria.
Jackson, C. R., Lubbe, N. R., Robertson, M. P., Setsaas, T. H., Bennett, N. C., \& Van Der Waals, J. H. (2007). Soil properties limiting the distribution of the critically endangered Juliana's Golden Mole (Neamblysomus julianae). Journal of Zoology, London, 274, 13-17.

Jackson, C. R., Setsaas, T. H., Robertson, M. P., \& Bennett, N. C. (2008). Ecological variables governing habitat quality and the distribution of the endangered Juliana's Golden Mole. African Zoology, 43, 245-255.

Jackson, C. R., Setsaas, T. H., Robertson, M. P., Scantlebury, M., \& Bennett, N. C. (2009). Insights into torpor and behavioural thermoregulation of the endangered Juliana's golden mole. Journal of Zoology, 278, 299-307.

Jiménez-Valverde, A., Lobo, J. M., \& Hortal, J. (2008). Not as good as they seem: The importance of concepts in species distribution modeling. Diversity and Distributions, $14,885-890$.

Loiselle, B. A., Howell, C. A., Graham, C. H., Goerck, J. M., Brooks, T., Smith, K. G., et al. (2003). Avoiding pitfalls of using species distribution models in conservation planning. Conservation Biology, 17, 1591-1600.

Margules, C. R., \& Pressey, R. L. (2000). Systematic conservation planning. Nature, 405, 243-253.

Mucina, L., \& Rutherford, M. C. (Eds.). (2006). The vegetation of South Africa, Lesotho and Swaziland. In Strelitzia 19. Pretoria: South African National Biodversity Institute.

Pearson, R. G., \& Dawson, T. P. (2003). Predicting the impacts of climate change on the distribution of species: Are bioclimate envelope models useful? Global Ecology and Biogeography, 12, 361-371.

Pearson, R. G., Raxworthy, C. J., Nakamura, M., \& Peterson, A. T. (2007). Predicting species distribution from small occurrence records: A test case using cryptic geckos in Madagascar. Journal of Biogeography, 34, 102-117.

Peterson, A. T. (2001). Predicting species' geographic distributions based on ecological niche modeling. The Condor, 103, 599-605

Phillips, S. J., Anderson, R. P., \& Schapire, R. E. (2006). Maximum entropy modeling of species geographic distributions. Ecological Modelling, 190, 231-259.

Phillips, S. J., \& Dudik, M. (2008). Modeling of species distributions with Maxent: New extensions and a comprehensive evaluation. Ecography, 31, 161-175.

$\mathrm{R}$ Development Core Team. (2005). R: A language and environment for statistical computing. Vienna, Austria: R Foundation for Statistical Computing. http://www.R-project.org

Rushton, S.P., Ormerod, S. J., \& Kerby, G. (2004). New paradigms for modelling species distributions? Journal of Applied Ecology, 41, 193-200.

Raxworthy, C. J., Ingram, C. M., Rabibisoa, N., \& Pearson, R. G. (2007). Applications of ecological niche modelling for species delimitation: A review and empirical evaluation using day geckos (Phelsuma) from Madagascar. Systematic Biology 56, 907-923.

Soberon, J., \& Peterson, A. T. (2005). Interpretation of models of fundamental ecological niches and species' distributional areas. Biodiversity Informatics, 2, 1-10.

Thomaes, A., Kervyn, T., \& Maes, D. (2008). Applying species distribution modelling for the conservation of the threatened saproxylic Stag Beetle (Lucanus cervus). Biological Conservation, 141, 1400-1410.

Titeux, N., Dufrene, M., Radoux, J., Hirzel, A. H., \& Defourny, P. (2007). Fitness-related parameters improve presence-only distribution modelling for conservation practice: The case of the red-backed shrike. Biological Conservation, 138 207-223.

Wilson, K. A., Wesphal, M. I., Possingham, H. P., \& Elith, J. (2005). Sensitivity of conservation planning to different approaches to using predicted species distribution data. Biological Conservation, 122, 99-112.

Wisz, M. S., Hijmans, R. J., Li, J., Peterson, A. T., Graham, C. H., \& Guisan, A. (2008) Effects of sample size on the performance of species distribution models. Diversity and Distributions, 14, 763-773. 